\title{
Stimulation of glycogen synthesis and inactivation of phosphorylase in hepatocytes by serotonergic mechanisms, and counter-regulation by atypical antipsychotic drugs
}

\author{
L. J. Hampson • P. Mackin • L. Agius
}

Received: 12 March 2007 / Accepted: 5 April 2007 / Published online: 20 June 2007

(C) Springer-Verlag 2007

\begin{abstract}
Aims/hypothesis Intraportal infusion of serotonin (5hydroxytryptamine, 5-HT) or inhibitors of its cellular uptake stimulate hepatic glucose uptake in vivo by either direct or indirect mechanisms. The aims of this study were to determine the direct effects of 5-HT in hepatocytes and to test the hypothesis that atypical antipsychotic drugs that predispose to type 2 diabetes counter-regulate the effects of 5-HT.

Materials and methods Rat hepatocytes were studied in short-term primary culture.

Results Serotonin (5-HT) stimulated glycogen synthesis at nanomolar concentrations but inhibited it at micromolar concentrations. The stimulatory effect was mimicked by $\alpha$ methyl-5-HT, a mixed 5-HT1/5-HT2 receptor agonist, whereas the inhibition was counteracted by a $5-\mathrm{HT} 2 \mathrm{~B} / 2 \mathrm{C}$ receptor antagonist. $\alpha$-Methyl-5-HT stimulated glycogen synthesis additively with insulin, but unlike insulin, did not stimulate glucose phosphorylation and glycolysis, nor did it cause Akt (protein kinase B) phosphorylation. Stimulation
\end{abstract}

L. J. Hampson · L. Agius

Institute of Cellular Medicine, Newcastle University,

The Medical School,

Newcastle upon Tyne, UK

P. Mackin

School of Neurology, Neurobiology and Psychiatry,

The Medical School,

Newcastle upon Tyne, UK

L. Agius $(\square)$

Institute of Cellular Medicine,

The Medical School (Leech, Level 4),

Framlington Place,

Newcastle upon Tyne NE2 4HH, UK

e-mail: Loranne.Agius@ncl.ac.uk of glycogen synthesis by $\alpha$-methyl-5-HT correlated with depletion of phosphorylase $a$. This effect could not be explained by elevated levels of glucose 6-phosphate, which causes inactivation of phosphorylase, but was explained, at least in part, by decreased phosphorylase kinase activity in situ. The antipsychotic drugs clozapine and olanzapine, which bind to 5-HT receptors, counteracted the effect of $\alpha$ methyl-5-HT on phosphorylase inactivation.

Conclusions/interpretation This study provides evidence for both stimulation and inhibition of glycogen synthesis in hepatocytes by serotonergic mechanisms. The former effects are associated with the inactivation of phosphorylase and are counteracted by atypical antipsychotic drugs that cause hepatic insulin resistance. Antagonism of hepatic serotonergic mechanisms may be a component of the hepatic dysregulation caused by antipsychotic drugs that predispose to type 2 diabetes.

Keywords 5-Hydroxytryptamine - Atypical antipsychotics . Glycogen · Liver · Phosphorylase · Serotonin ·

Type 2 diabetes

\section{Abbreviation \\ 5-HT 5-hydroxytryptamine}

\section{Introduction}

Serotonin (5-hydroxytryptamine, 5-HT) is a monoamine neurotransmitter in the central and autonomic nervous systems that also functions as a hormone. It is abundant in platelets, which store 5-HT at high concentration, and in the enterochromaffin cells of the gut, which are the main source of circulating 5-HT [1]. It has diverse physiological 
effects that are mediated centrally and peripherally through seven types (5-HT1 to 5-HT7) and several subtypes of receptor $[2,3]$. With the exception of the type-3 receptors, which are coupled to ligand-gated ion channels, the 5-HT receptors are coupled to the G-proteins Gs, Gi and Gq [1-3].

In addition to its role as a neurotransmitter, 5-HT has a range of functions that include control of vascular tone, exocrine secretion by the pancreas [4], liver regeneration [5] and glucose homeostasis [6-8]. Studies in vivo have shown either hypoglycaemia [6, 7] or hyperglycaemia [8] after administration of 5-HT. The latter is attributed to release of epinephrine from the adrenal glands or to vasoconstrictor effects. However, the mechanisms that account for hypoglycaemia [6, 7] or improved glucose tolerance in diabetes after treatment with selective 5-HT reuptake inhibitors [9] are not fully understood. In skeletal muscle 5-HT has been found to either stimulate or to have no effect on glucose uptake $[10,11]$. However, in the liver, intraportal infusion of 5-HT or its precursor, 5-hydroxytryptophan, stimulated glucose uptake during a hyperinsulinaemic clamp [12, 13]. Stimulation of hepatic glucose uptake with concomitant glycogen storage also occurred during infusion of a selective 5-HT reuptake inhibitor during a hyperinsulinaemic clamp but not during euinsulinaemic clamps $[14,15]$. This could be due to a direct effect of 5-HT on hepatocytes or to indirect mechanisms involving either haemodynamic changes or decreased afferent signalling. Although there is evidence that 5-HT inhibits the discharge rate of the vagal hepatic afferent innervation [16], little is known about direct effects of 5-HT on hepatocytes $[17,18]$.

The aim of this study was to test whether 5-HT exerts direct effects on glucose metabolism in hepatocytes that could be involved in the stimulation of hepatic glucose uptake during intraportal infusion of 5-HT [12]. A further aim was to test whether the second-generation (atypical) antipsychotic drugs, which pose a high risk of development of type 2 diabetes [19-21] and are known to interact with a broad range of 5-HT receptors, counter-regulate the effects of 5-HT on hepatocytes.

\section{Materials and methods}

Materials Serotonin (5-HT) was from Sigma (St Louis, MO). Clozapine, 5-HT receptor antagonists ((S)-WAY 100135, SB 224289, BRL 15572, ketanserin, ritanserin, SB 206553, SB 204741, MDL 72222, GR 113808, SB 258585 and SB 269970) and agonists ( $\alpha$-methyl-5-HT, L694,247) were from Tocris Bioscience, Avonmouth, UK. Olanzapine and CP-91149 [22] were kind gifts from Eli Lilly (Indianapolis, IN) and Pfizer Global Research and Development (Groton/New London Laboratories, Groton, CT), respectively.
Primary hepatocyte culture Male Wistar rats (body weight 200-280 g) were from B \& K (Hull, UK). Hepatocytes were isolated by collagenase perfusion of the liver [23], suspended in Minimal Essential Medium (MEM) with 5\% (v/v) neonatal calf serum and plated in multiwell plates. After cell attachment $(4 \mathrm{~h})$, the medium was replaced with serum-free MEM containing $10 \mathrm{nmol} / 1$ dexamethasone and $5 \mathrm{mmol} / \mathrm{l}$ glucose and the cells were cultured for $16 \mathrm{~h}$.

Metabolic incubations For determination of glycogen synthesis, glucose phosphorylation and glycolysis, the hepatocytes were incubated for $3 \mathrm{~h}$ in MEM containing $15 \mathrm{mmol} /$ 1 glucose and the additions indicated. With the exception of 5-HT and $\alpha$-methyl-5-HT, all receptor agonists and antagonists and CP-91149 were dissolved in DMSO. The final DMSO concentration in all incubations was $0.1 \% \mathrm{v} / \mathrm{v}$. For the determination of glycogen synthesis, glycolysis and glucose phosphorylation the medium was supplemented with $\left[\mathrm{U}-{ }^{14} \mathrm{C}\right]$ glucose, $\left[3-{ }^{3} \mathrm{H}\right]$ glucose or $\left[2-{ }^{3} \mathrm{H}\right]$ glucose $(37-74 \mathrm{kBq} / \mathrm{ml})$ respectively. Glycogen synthesis was determined from the incorporation of ${ }^{14} \mathrm{C}$ label into glycogen, determined by ethanol precipitation [23], and glycolysis and glucose phosphorylation were determined from the rate of formation of ${ }^{3} \mathrm{H}_{2} \mathrm{O}$ [24]. Parallel incubations without radiolabel were performed for the determination of glucose 6-phosphate [25] and glycogen synthase and phosphorylase.

Enzyme assays On termination of the incubations the medium was aspirated and the plates were snap-frozen in liquid nitrogen and stored at $-80^{\circ} \mathrm{C}$. For the determination of phosphorylase $a$, the cells were extracted as described by Aiston et al. [23] and phosphorylase $a$ was assayed spectrometrically in the $13,000 \mathrm{~g}$ supernatant [15]; activity is expressed as $\mathrm{mU} / \mathrm{mg}$ protein. For determination of glycogen synthase, cells were extracted and enzyme activity was determined radiochemically from the incorporation of UDP-[6- $\left.{ }^{3} \mathrm{H}\right]$-glucose, as described by Aiston et al. [23]. Activity was determined in the absence of glucose 6phosphate and is expressed as $\mathrm{mU} / \mathrm{mg}$ protein.

Western blotting On termination of incubation the cells were snap-frozen in liquid nitrogen and stored at $-80^{\circ} \mathrm{C}$. The cells were extracted in gel-loading buffer containing $15 \%$ sucrose, $2 \%$ SDS, bromophenol blue and $1 \%$ mercaptoethanol, separated by $10 \%$ SDS-PAGE and transferred to nitrocellulose membranes. Membranes were blocked for $2 \mathrm{~h}$ in 3\% BSA and incubated overnight with a phosphospecific antibody against Akt (protein kinase B) serine 473 (New England BioLabs, Beverly, MA) followed by horseradish peroxidase-linked anti-IgG (Jackson Immunoresearch, Westgrove, PA) [26]. Immunoreactive bands were detected using an enzyme chemiluminescence kit (Amersham Biosciences, Little Chalfont, UK). 
Data analysis Results are presented as means \pm SEM for the number of hepatocytes preparations indicated. Statistical analysis was by the Student's paired $t$ test or one- or two-way ANOVA.

\section{Results}

5-HT exerts inhibitory and stimulatory effects on glycogen synthesis The concentration of 5-HT in whole blood is about 3-6 $\mu \mathrm{mol} / 1$ [12] whilst that in platelet-free plasma is in the nanomolar range $[27,28]$. To determine the direct effects of 5-HT on hepatocytes, we initially tested concentrations in the range of $0.2-10 \mu \mathrm{mol} / 1$ in the absence or presence of insulin or a counter-regulatory concentration of glucagon to mimic the conditions in previous physiological studies [12]. 5-HT inhibited glycogen synthesis at concentrations of $1-10 \mu \mathrm{mol} / 1$ and it inhibited glucose phosphorylation and glycolysis at $10 \mu \mathrm{mol} / 1$ in the three hormonal conditions tested (Fig. 1a-c). The inhibition of glycogen synthesis was partially counteracted by SB206553, a 5$\mathrm{HT} 2 \mathrm{~B} / 2 \mathrm{C}$ receptor antagonist (Fig. 1d). At the lowest concentration tested $(0.2 \mu \mathrm{mol} / \mathrm{l}), 5-\mathrm{HT}$ stimulated glycogen synthesis in the presence of insulin in two of the five experiments shown in Fig. 1a. In further experiments we tested the effects of lower concentrations (10-100 nmol/l) of $5-\mathrm{HT}$ in the presence of insulin. At $50 \mathrm{nmol} / \mathrm{l}, 5-\mathrm{HT}$ caused a small but significant stimulation of glycogen synthesis (Fig. 2a). This effect was partly counteracted by SB224289, a 5-HT1B receptor antagonist, but not by the 5$\mathrm{HT} 2 \mathrm{~B} / 2 \mathrm{C}$ receptor antagonist (Fig. 2a).

Stimulation of glycogen synthesis by $\alpha$-methyl-5-HT An agonist of the 5-HT1B receptor $($ L-694,247) stimulated glycogen synthesis $(p<0.05)$, and this effect was partially counteracted by the 5-HT1B receptor antagonist (Fig. 2b). The mixed 5-HT1/5-HT2 agonist $\alpha$-methyl-5-HT [29] also stimulated glycogen synthesis, by $61 \%$; this effect was partially counteracted by the 5-HT1B antagonist but not by the 5-HT2B/2C antagonist (Fig. 2c). Because $\alpha$-methyl-5HT mimicked the stimulatory but not the inhibitory effects

Fig. 1 Inhibition of glycogen synthesis, glucose phosphorylation and glycolysis by micromolar concentrations of 5-HT in hepatocytes. Hepatocytes were incubated for $3 \mathrm{~h}$ with the concentrations of 5-HT indicated (open bars 0; hatched bars 0.2; grey bars 1; filled bars $10 \mu \mathrm{mol} / \mathrm{l}$ ) either in the absence of hormones (control) or in the presence of $10 \mathrm{nmol} / 1$ insulin without or with $1 \mathrm{nmol} / 1$ glucagon for the determination of glycogen synthesis (a), glucose phosphorylation (b) and glycolysis (c). d Effects of 5-HT on glycogen synthesis in the absence of hormones and without (open bars) or with (filled bars) $1 \mu \mathrm{mol} / 1 \mathrm{SB} 206553$, a 5-HT2B/2C antagonist. Means \pm SEM, $n=4-6$ experiments. ${ }^{*} p<0.05,{ }^{*} p<0.005$ vs no 5 -HT of 5-HT, this agonist was used in the rest of this study to investigate the stimulatory mechanism in the absence of interference from the inhibitory effects mediated by the 5$\mathrm{HT} 2 \mathrm{~B} / 2 \mathrm{C}$ receptors. a
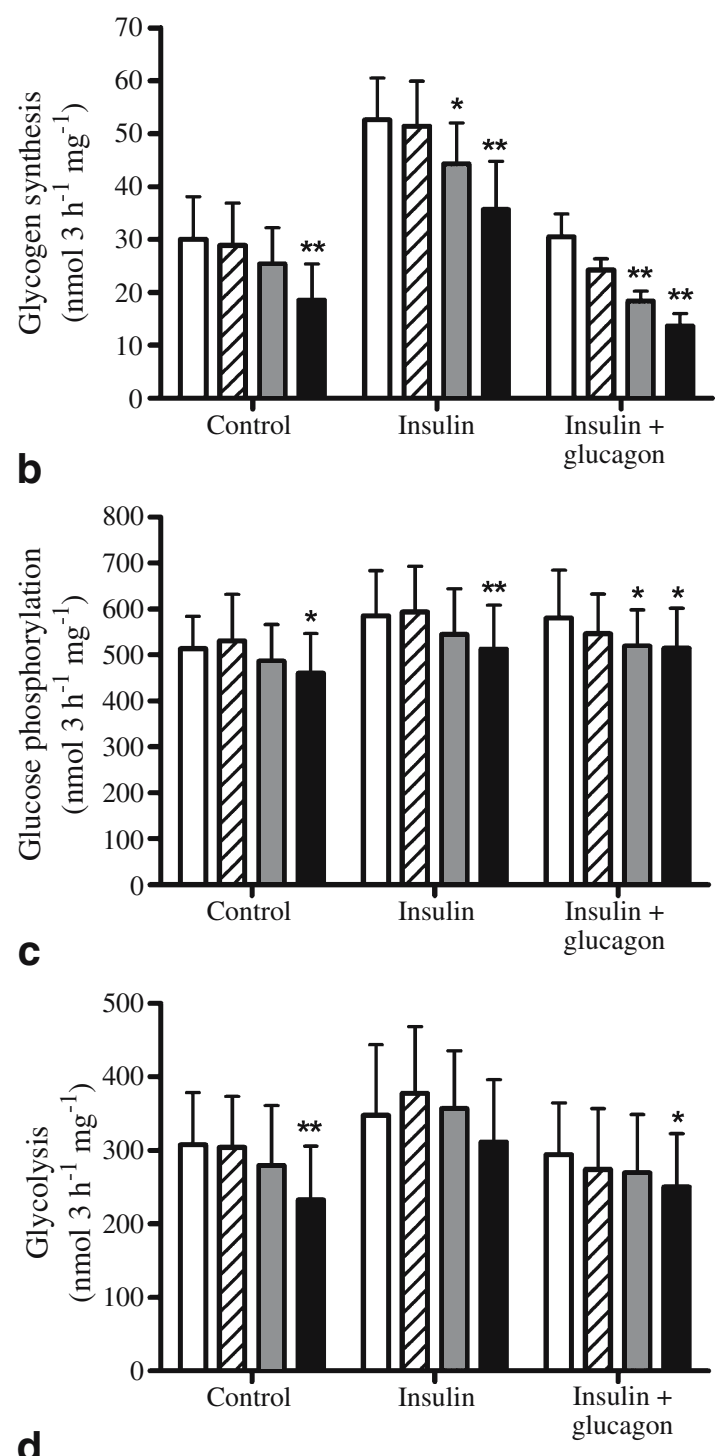

d

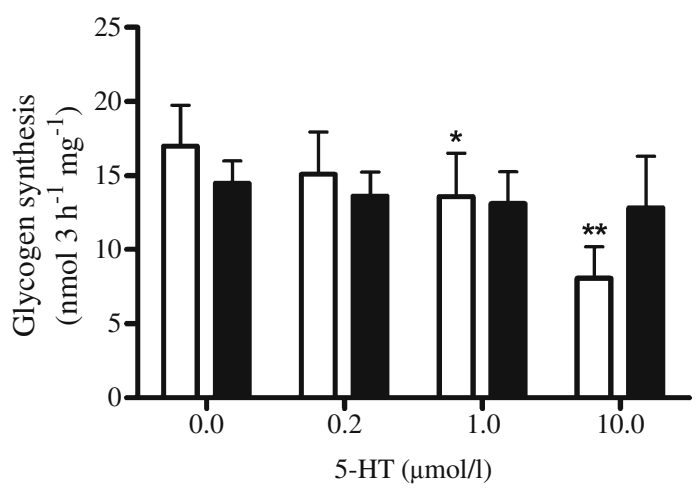


a

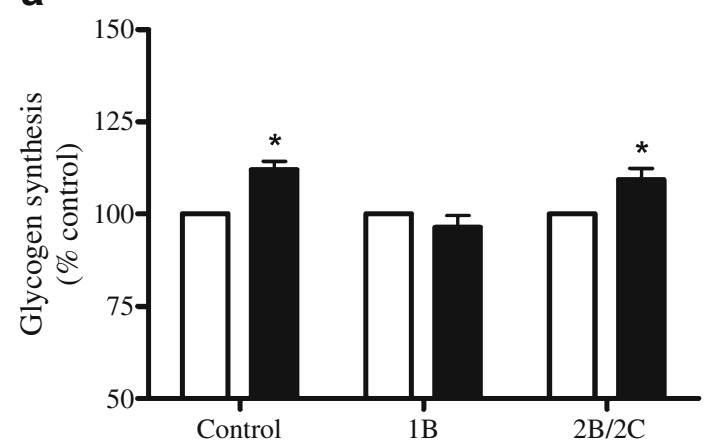

b

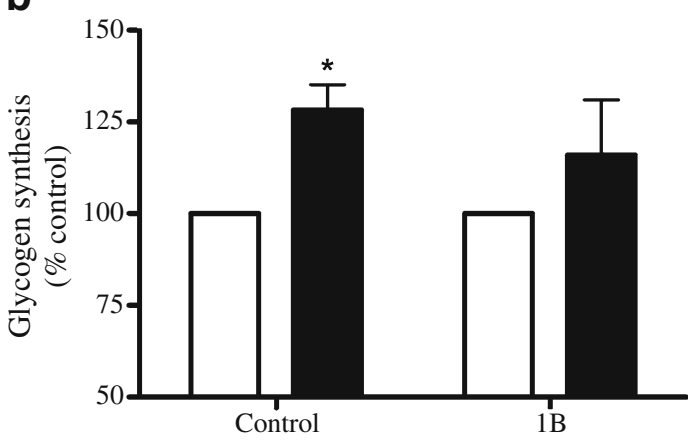

C

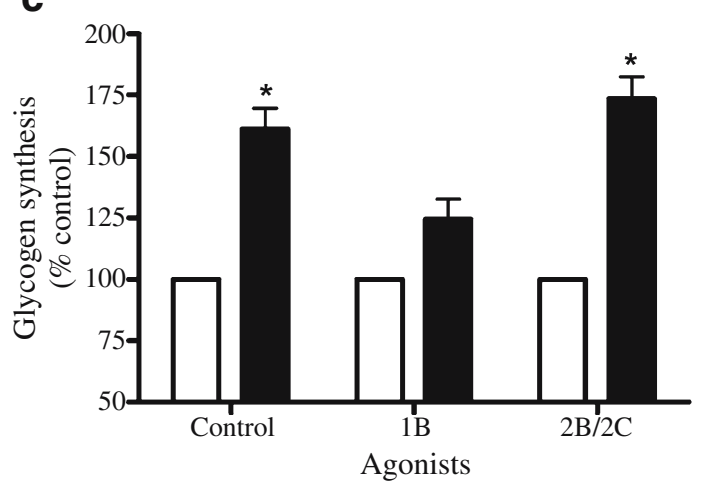

Fig. 2 Stimulation of glycogen synthesis by 5-HT, a 5HT-1B receptor agonist and $\alpha$-methyl-5-HT. a Absence (open bars) and presence (filled bars) of $50 \mathrm{nmol} / 15-\mathrm{HT}$. b Absence (open bars) and presence (filled bars) of $1 \mu \mathrm{mol} / 1 \mathrm{~L} 694247$ (5-HT1B agonist). c Absence (open bars) and presence (filled bars) of $10 \mu \mathrm{mol} / 1 \alpha$-methyl-5-HT, in the presence of antagonists of the 5-HT1B receptor $(1 B ; 1 \mu \mathrm{mol} / 1 \mathrm{SB} 224289)$ and 5HT2B/2C receptor $(2 B / 2 C ; 1 \mu \mathrm{mol} / 1 \mathrm{SB} 206553)$. Means \pm SEM, $n=4-6$ experiments. ${ }^{*} p<0.05$ for effects of agonist

$\alpha$-Methyl-5-HT does not mimic insulin action on glucose phosphorylation and glycolysis $\alpha$-Methyl-5-HT $(10 \mu \mathrm{mol} / \mathrm{l})$ stimulated glycogen synthesis additively with insulin (Fig. 3a) and this was associated with inactivation of phosphorylase (Fig. 3b). Unlike insulin, it did not stimulate glucose phosphorylation and glycolysis and partially counteracted the stimulation by insulin (Fig. 3c, d). The lack of stimulation of glucose phosphorylation was further supported by a lack of effect on the cell content of glucose 6-phosphate (control, $0.71 \pm 0.16 \mathrm{nmol} / \mathrm{mg} ; \alpha$-methyl-5-HT, $0.71 \pm 0.08 \mathrm{nmol} / \mathrm{mg}$ ). Because 5-HT1 receptors are coupled to Gi [3], we tested the a

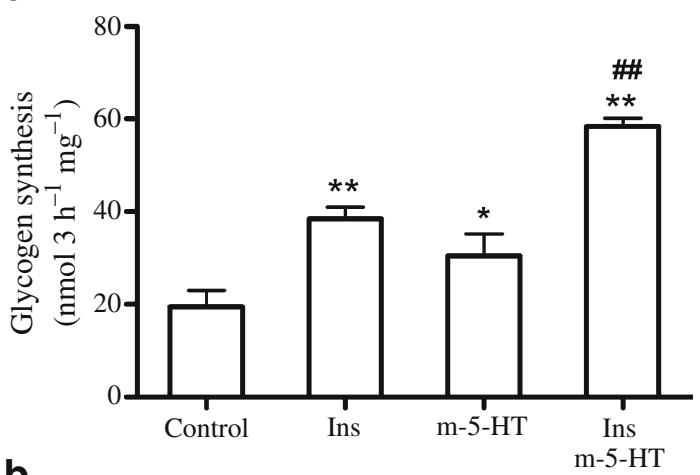

b
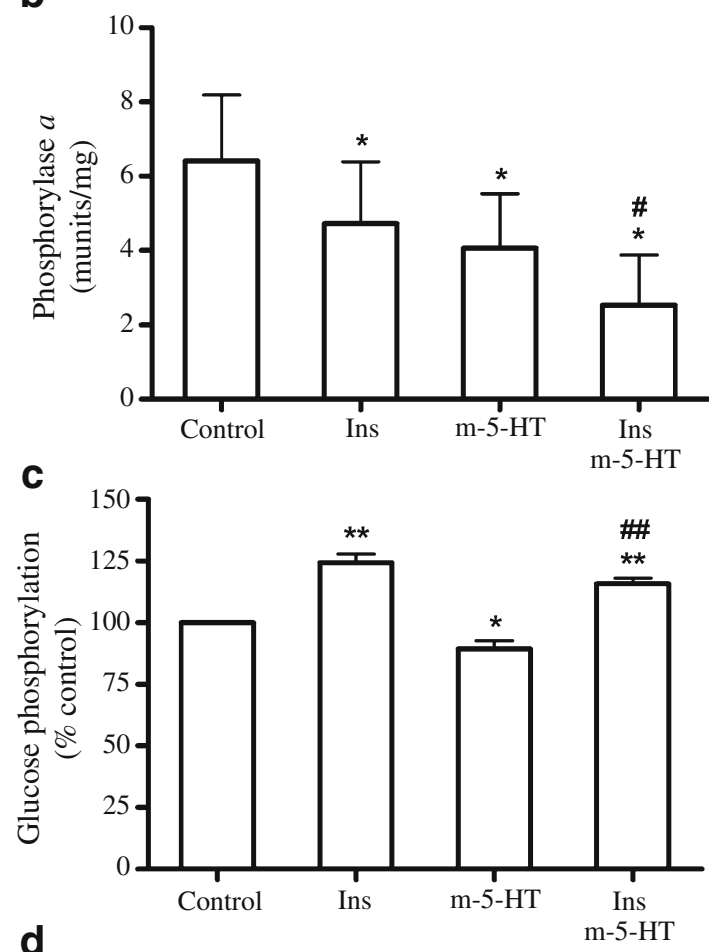

d

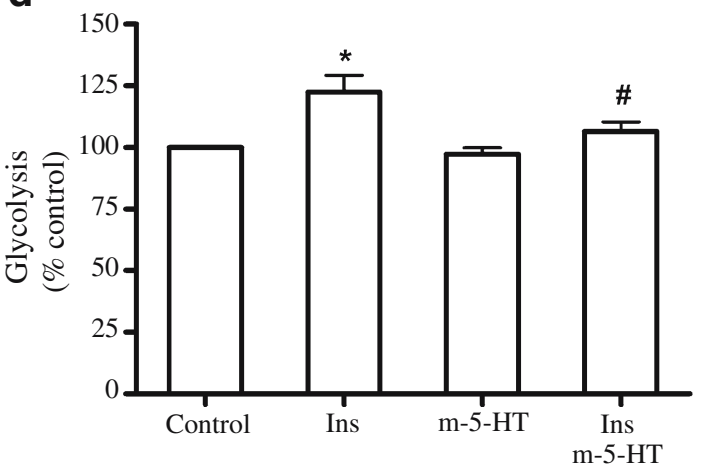

Fig. $3 \alpha$-Methyl-5-HT $(m-5-H T)$ and insulin (Ins) cause additive stimulation of glycogen synthesis and inactivation of phosphorylase. Hepatocytes were incubated with insulin $(10 \mathrm{nmol} / \mathrm{l})$ and/or $\alpha$-methyl5-HT $(10 \mu \mathrm{mol} / \mathrm{l})$ for determination of glycogen synthesis (a), phosphorylase $a$ activity (b), glucose phosphorylation (c) and glycolysis (d). Means \pm SEM, $n=4$ experiments. ${ }^{*} p<0.05,{ }^{*} p<0.005$ vs no additions; ${ }^{\#} p<0.05,{ }^{\#} p<0.005$ vs insulin alone

effects of pertussis toxin (PT) $(0.3 \mu \mathrm{g} / \mathrm{ml})$, which uncouples some Gi-mediated pathways [3]. The stimulation of glycogen 
synthesis by $\alpha$-methyl-5HT was partially counteracted in cells precultured with pertussis toxin (control, 19.5 \pm 3.5 ; PT, $17.1 \pm 4.4 ; \alpha$-methyl-5-HT, $30.5 \pm 4.7$; PT $+\alpha$-methyl-5-HT, $26.0 \pm 6.0[p<0.05$ absence vs presence of PT]; mean \pm SEM, $n=4$ ), consistent with partial involvement of a Gi-mediated mechanism.

Role of phosphorylase inactivation in mediating the glycogenic action of $\alpha$-methyl-5-HT To determine the contribution of phosphorylase inactivation (conversion of phosphorylase $a$ to phosphorylase $b$ ) to the glycogenic action of $\alpha$-methyl-5-HT we used the indole carboxamide CP-91149, a selective phosphorylase inhibitor that causes depletion of phosphorylase $a$ by dephosphorylation [22,23]. The effects of different concentrations of CP-91149 on glycogen synthesis and phosphorylase $a$ activity were determined in the absence or presence of insulin or $\alpha$-methyl-5-HT. CP-91149 stimulated glycogen synthesis and inactivated phosphorylase (Fig. 4a, b) in all three experimental conditions. Whereas insulin stimulated glycogen synthesis by more than could be explained by inactivation of phosphorylase alone, as shown by the upward shift in the curve (Fig. 4c), the correlations between glycogen synthesis and phosphorylase $a$ in the absence and presence of $\alpha$-methyl-5-HT were superimposable, indicating that stimulation by $\alpha$-methyl-5-HT can be fully explained by depletion of phosphorylase $a$ (Fig. 4c). $\alpha$-Methyl-5-HT, like insulin, activated glycogen synthase (control, $0.34 \pm 0.08 \mathrm{mU} / \mathrm{mg} ; \alpha$ methyl-5-HT, $0.61 \pm 0.15 \mathrm{mU} / \mathrm{mg}[p<0.05$ relative to control]; insulin, $0.58 \pm 0.14 \mathrm{mU} / \mathrm{mg}[p<0.05$ relative to control]). Activation of glycogen synthase by both insulin and $\alpha$ methyl-5-HT in the presence of CP-91149 was greater than could be explained by depletion of phosphorylase $a$ alone (Fig. 4d). Activation of glycogen synthase by CP-91149 is explained by depletion of phosphorylase $a$, which is a potent inhibitor of glycogen synthase phosphatase [23]. The greater activation of glycogen synthase by $\alpha$-methyl-5-HT indicates an effect on glycogen synthase additional to depletion of phosphorylase $a$.

Mechanism of inactivation of phosphorylase by $\alpha$-methyl-5-HT Inactivation of phosphorylase by insulin in hepatocytes occurs downstream of activation of Akt and is associated with phosphorylation of serine 473 [26]. However, $\alpha$-methyl-5-HT, unlike insulin, did not cause Akt phosphorylation (Fig. 5). The effect of $\alpha$-methyl-5-HT on phosphorylase inactivation was rapid and increased progressively with time (Fig. 6a). A possible mechanism for the inactivation of phosphorylase is through changes in the concentrations of metabolites that bind to phosphorylase. Allosteric ligands of phosphorylase, such as glucose and glucose 6-phosphate, which favour the T (tense) conformation, cause dephosphorylation (inactivation) because the $\mathrm{T}$ state is a better substrate for dephosphorylation than the relaxed (R) conformation [30]. Conversely, AMP, which
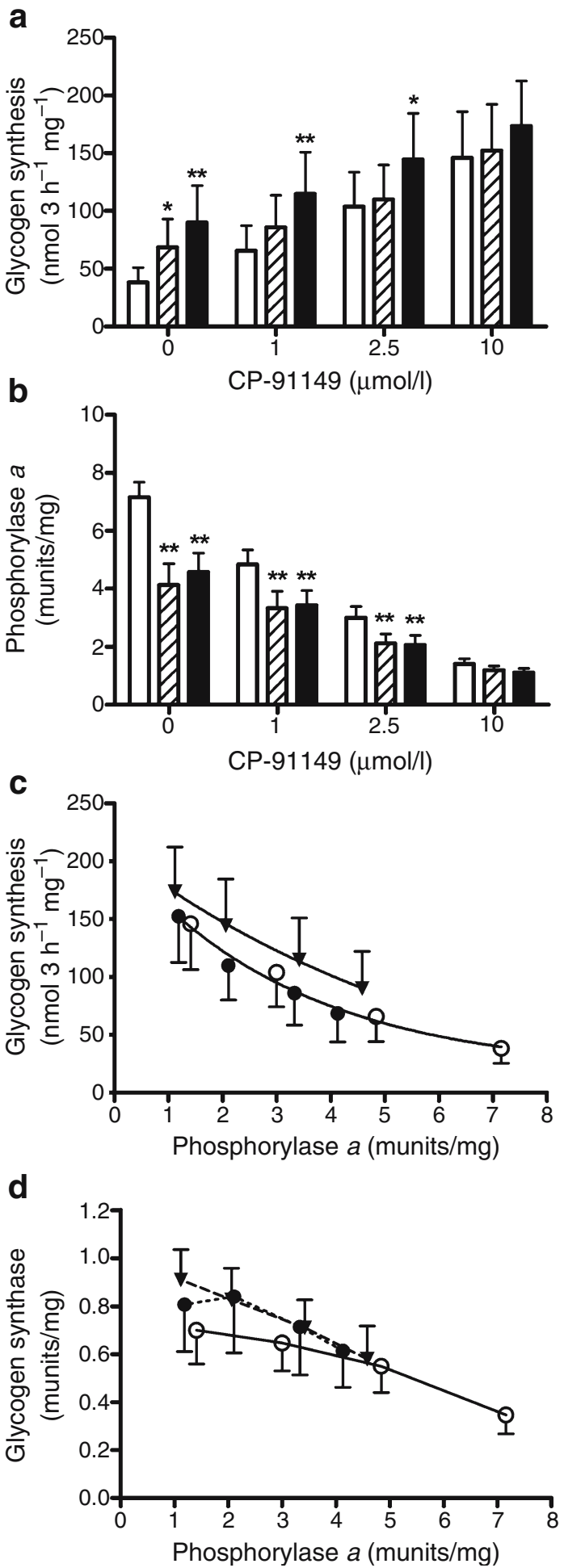

Fig. 4 Stimulation of glycogen synthesis by m-5-HT correlates with depletion of phosphorylase $a$. Hepatocytes were incubated with the concentrations of CP-91149 indicated in the absence (open bar, open circle) or presence of $10 \mu \mathrm{mol} / \mathrm{l} \alpha$-methyl-5-HT (hatched bar, filled circle) or $10 \mathrm{nmol} / 1$ insulin (filled bar, filled triangle). a Glycogen synthesis. b Phosphorylase $a$ activity. c Glycogen synthesis vs phosphorylase a activity. d Glycogen synthase vs phosphorylase a activity. Means \pm SEM, $n=3-4$ experiments. $* p<0.05 ; * * p<0.005$ relative to corresponding control 


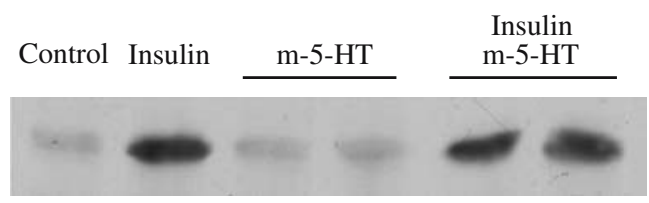

P-Akt

(Serine 473)

Fig. 5 Insulin but not $\alpha$-methyl-5-HT (m-5-HT) increases Akt phosphorylation. Hepatocytes were incubated with $10 \mathrm{nmol} / 1$ insulin and/or $10 \mu \mathrm{mol} / \mathrm{l} \alpha$-methyl-5-HT for $30 \mathrm{~min}$ and immunoblotted for Akt-phosphorylated (P-Akt) serine 473

induces the $\mathrm{R}$ state, favours phosphorylation. Since these metabolites act synergistically (glucose 6-phosphate) or antagonistically (AMP) with the indole carboxamide inhibitor CP-91149, which also favours the $T$ state $[22,31]$, we tested whether $\alpha$-methyl-5-HT alters the affinity for CP-91149. However, $\alpha$-methyl-5-HT did not affect the affinity $\left(\mathrm{EC}_{50}\right)$ for CP-91149 (control, $1.56 \pm 0.04 \mu \mathrm{mol} / 1 ; 10 \mu \mathrm{mol} / 1 \mathrm{Me}-5-\mathrm{HT}$, $1.40 \pm 0.13 \mu \mathrm{mol} / \mathrm{l}$; means $\pm \mathrm{SEM}, n=4)$, suggesting that phosphorylase inactivation by $\alpha$-methyl-5-HT is unlikely to be due to altered concentrations of phosphorylase ligands.

Because the metabolic actions of $\alpha$-methyl-5-HT share similarities with the antihyperglycaemic drug proglycosyn and its analogue resorcinol [32], which stimulate glycogen synthesis and inactivate phosphorylase but do not stimulate glycolysis, we tested the combined effects of resorcinol and $\alpha$-methyl-5-HT on phosphorylase $a$. Resorcinol caused inactivation of phosphorylase $a$ with half-maximal effect at $\sim 10 \mu \mathrm{mol} / \mathrm{l}$. The effects of submaximal concentrations of $\alpha$-methyl-5-HT and resorcinol were additive but not synergistic and $\alpha$-methyl-5-HT did not affect the affinity for resorcinol $\left(\mathrm{EC}_{50}, 12.2 \pm 0.9\right.$ vs $\left.9.4 \pm 0.6 \mu \mathrm{mol} / \mathrm{l}\right)$.

The inactivation of phosphorylase by proglycosyn and resorcinol is due, at least in part, to inhibition of phosphorylase kinase [32]. We therefore tested whether $\alpha$ methyl-5-HT affects phosphorylase kinase activity by determining the time course of activation of phosphorylase in hepatocytes after addition of calyculin A, an inhibitor of type- 1 and type-2A protein phosphatases (Fig. 6b). The rate of activation of phosphorylase after addition of calyculin A was slower in the presence of $\alpha$-methyl-5-HT, as shown by the smaller increment in phosphorylase $a$ during the first 2 min after addition of calyculin A (4.6 \pm 1.3 vs $9.0 \pm$ $0.8 \mathrm{mU} / \mathrm{mg}$ protein, $p<0.05)$ suggesting lower activity of phosphorylase kinase.

Counteraction of the effects of $\alpha$-methyl-5-HT by clozapine and olanzapine We tested the effects of the atypical antipsychotic drugs clozapine and olanzapine on $\alpha$-methyl-5-HT-induced inactivation of phosphorylase (Fig. 7a,b). These drugs increase the risk of development of type 2 diabetes [19] and induce hepatic insulin resistance after both chronic and acute exposure [20, 21]. They differ from other antipsychotic drugs in their broad affinity for 5-HT receptors [2]. Both clozapine and olanzapine counteracted the inactivation of phosphorylase caused by $\alpha$-methyl-5-HT but had negligible effect in control conditions (Fig. 7). These drugs were more effective in counteracting the effect of $\alpha$-methyl-5-HT than selective antagonists of type- 1 and type- 2 5HT receptors, which counteracted the stimulation by $\alpha$-methyl-5-HT by between 18 and 54\% (5-HT1A, $1 \mu \mathrm{mol} / \mathrm{l}(S)$-WAY 100135, $18 \pm 3 \%$; 5-HT1B, $1 \mu \mathrm{mol} / 1$ SB 224289, 54 $\pm 5 \%$; 5-HT1D, $1 \mu \mathrm{mol} / 1 \mathrm{BRL} 15572,32 \pm 9 \%$; 5-HT2, $1 \mu \mathrm{mol} / 1$ ketanserin, $44 \pm 3 \%$; 5-HT2A, $1 \mu \mathrm{mol} / 1$ ritanserin, $29 \pm 7 \%$ ).

\section{Discussion}

Physiological studies by Moore and colleagues demonstrated increased hepatic glucose uptake after intraportal infusion of 5-HT or selective 5-HT uptake inhibitors [1215]. This raised the question whether these effects are mediated by a direct effect of 5-HT on hepatocytes or by indirect mechanisms involving haemodynamic changes or altered transmission of afferent signals. In this study we

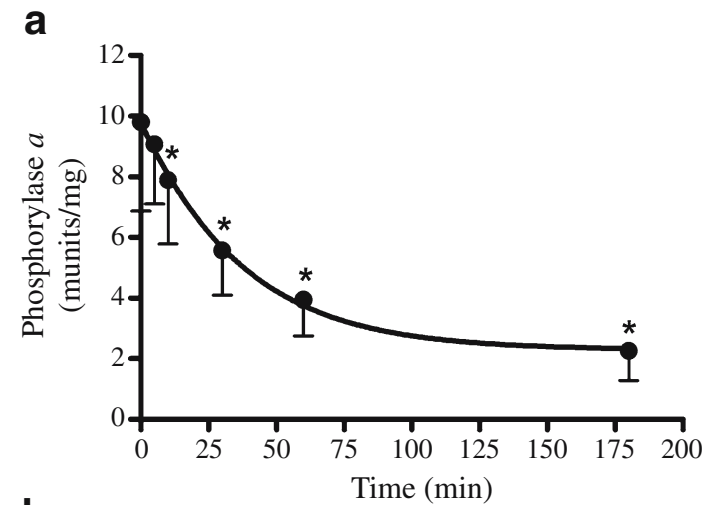

b

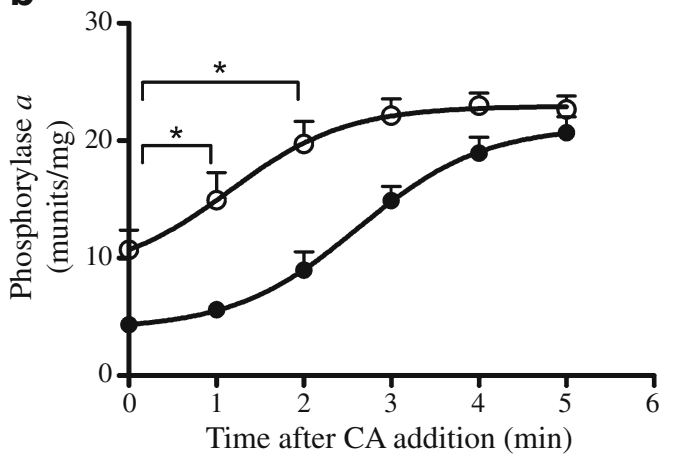

Fig. $6 \alpha$-Methyl-5-HT causes progressive inactivation of phosphorylase $a$ and counteracts the activation of phosphorylase by calyculin A. a Time course of inactivation of phosphorylase $a$ by $100 \mu \mathrm{mol} / 1 \alpha$ methyl-5-HT. b Time course of activation of phosphorylase after addition of $100 \mathrm{nmol} / 1$ calyculin $\mathrm{A}$ in cells preincubated (60 min) without (open symbols) or with (closed symbols) $100 \mu \mathrm{mol} / 1 \alpha$ methyl-5-HT. Means \pm SEM, $n=4$ (a) and $n=3$ (b) experiments. ${ }^{*} p<$ 0.05 vs time zero 
a

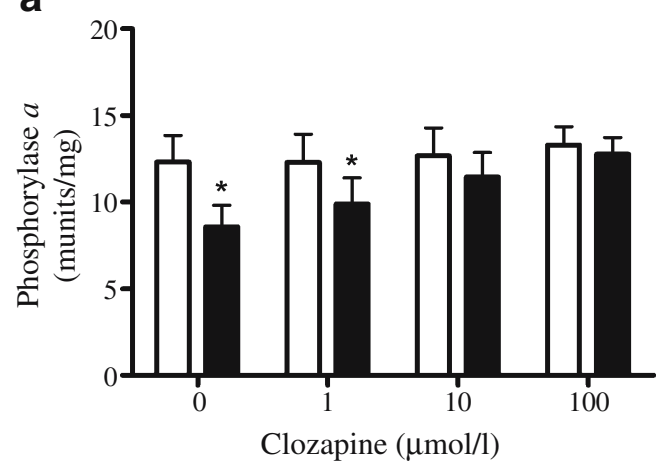

b

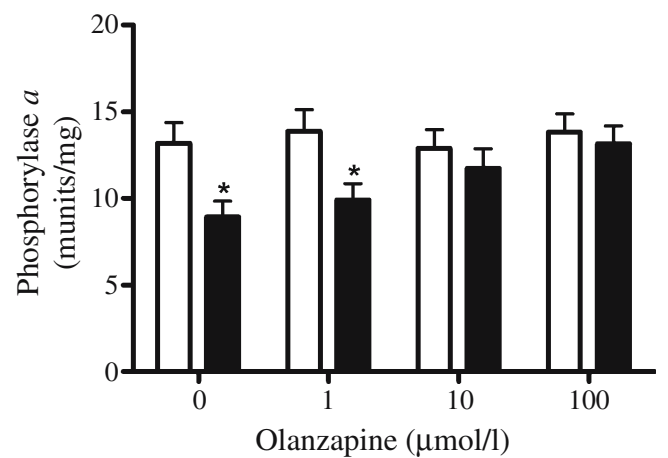

Fig. 7 Clozapine and olanzapine counteract the inactivation of phosphorylase by $\alpha$-methyl-5-HT (m-5-HT). Hepatocytes were preincubated with the concentrations of clozapine (a) and olanzapine (b) indicated for $30 \mathrm{~min}$ and then without (open bar) or with (filled bar) $10 \mu \mathrm{mol} / 1 \alpha$-methyl-5-HT for $60 \mathrm{~min}$. Means $\pm \mathrm{SEM}, n=4$. ${ }^{*} p<0.05$ vs respective control

show that 5-HT has direct inhibitory effects on glycogen synthesis in hepatocytes at micromolar concentrations but stimulatory effects at nanomolar concentrations. Whereas the concentration of 5-HT in whole blood is in the micromolar range, that in platelet-free plasma is in the nanomolar range because 5-HT is sequestered in platelets. The plasma 5-HT concentration is about $20-30 \mathrm{nmol} / 1$ in the fasted state and increases two- to fourfold after a high-carbohydrate meal [27, 28]. Stimulation of glycogen synthesis by 5-HT in hepatocytes therefore occurs at plasma concentrations attained in the absorptive state [27].

Evidence for glycogenolytic effects in the perfused rat liver [17] or elevation of cAMP and induction of phosphoenolpyruvate carboxykinase mRNA in hepatocytes [18] by micromolar concentrations of 5-HT has been reported. Accordingly, the inhibition of glycogen synthesis and glycolysis by micromolar 5 -HT could be mediated by elevated $\mathrm{Ca}^{2+}$ or cAMP [18]. Since the 5-HT2 receptors are coupled to activation of phospholipase $\mathrm{C}$ via $\mathrm{Gq}$ whereas the 5HT4, 5-HT6 and 5-HT7 receptors are coupled to cAMP formation via Gs [3], either of these receptors may be involved in the inhibition of glycogen synthesis. The partial counteraction of the inhibition of glycogen synthesis by the $5-\mathrm{HT} 2 \mathrm{~B} / 2 \mathrm{C}$ antagonist indicates involvement of type- 2 receptors in mediating the inhibition of glycogen synthesis. 5-HT stimulates cell proliferation in various cell types, including hepatocytes [33], at micromolar concentrations through 5-HT2A and 5-HT2B receptors. High concentrations of 5-HT occur in vivo during tissue injury, when platelet aggregation results in the release of stored 5HT. This mechanism is involved in liver regeneration after partial hepatectomy [5]. Since glycogenesis is suppressed during liver regeneration [34], high concentrations of 5-HT may have a dual role in suppressing glycogenesis and stimulating hepatocyte proliferation $[5,34]$.

Because of the opposite effects of 5-HT on glycogen synthesis (stimulation at nanomolar and inhibition at micromolar concentrations), we used a 5-HT analogue that mimics only the stimulation of glycogen synthesis to study the latter mechanism. This analogue has been shown to mimic the stimulation of glucose transport by $5-\mathrm{HT}$ in skeletal muscle [10]. Various lines of evidence show that $\alpha$ methyl-5-HT does not mimic insulin action. First, stimulation of glycogen synthesis was not associated with stimulation of glucose phosphorylation. Second, it was not associated with Akt phosphorylation. Finally, stimulation of glycogen synthesis by $\alpha$-methyl-5-HT was additive with the effect of a maximally effective insulin concentration, indicating independent convergent mechanisms. This is similar to the additive effects of $\alpha$-methyl-5-HT and insulin on glucose transport in L6 myotubes [10].

The stimulation of glycogen synthesis by $\alpha$-methyl-5-HT in hepatocytes can be explained by inactivation of phosphorylase. This is supported by two sets of evidence: first, the lack of stimulation of glucose phosphorylation and the lack of increase in the cell content of glucose 6-phosphate, a regulator of glycogen synthase; second, the inverse correlation between the rate of glycogen synthesis and the activity of phosphorylase $a$, irrespective of whether the hepatocytes were incubated with the selective phosphorylase ligand (CP-91149) alone or in the additional presence of $\alpha$-methyl-5-HT. The activation state of phosphorylase is determined by the activities of phosphorylase kinase and phosphorylase phosphatase and their association with glycogen targeting proteins, and also by the concentrations of ligands of phosphorylase (such as glucose 6-phosphate and AMP) that favour the $\mathrm{T}$ (tense) or the R (relaxed) state of phosphorylase. The former conformation is a better substrate for dephosphorylation, and accordingly an increase in glucose 6-phosphate or a decrease in AMP results in depletion of phosphorylase $a$. The inactivation of phosphorylase caused by $\alpha$-methyl-5-HT is unlikely to be due to changes in concentrations of endogenous ligands of phosphorylase because of the unchanged cell content of glucose 6-phosphate and the lack of synergy with the indole 
carboxamide inhibitor [31]. The metabolic effects of $\alpha$ methyl-5-HT in hepatocytes show various similarities to the actions of the antidiabetic drug proglycosyn and its analogue resorcinol, which cause inactivation of phosphorylase, in part through inhibition of phosphorylase kinase [32]. A decrease in phosphorylase kinase activity may also be involved in the inactivation of phosphorylase by $\alpha$-methyl-5-HT, as shown by the slower rate of activation of phosphorylase during inhibition of protein phosphatases. The apparent greater activation of glycogen synthase by $\alpha$-methyl-5-HT compared with the phosphorylase inhibitor is also consistent with inactivation of phosphorylase kinase, which causes phosphorylation and inactivation of glycogen synthase [35]. Studies on the brain have shown that 5-HT and fluoxetine, a selective serotonin reuptake inhibitor [36], cause acute and chronic changes in the phosphorylation state of the protein phosphatase-1 inhibitor DARPP-32 (dopamine and cyclic AMP regulated phosphoprotein, $32 \mathrm{kDa}$ ) which is a homologue of inhibitor-1. This protein is involved in the control of glycogen metabolism in adipose tissue [37] and, depending on its phosphorylation state, can function as a potent inhibitor of protein phosphatase-1 or of cAMP dependent protein kinase [38]. A change in the phosphorylation state of this protein or homologue thereof could in principle account for the decrease in activity of phosphorylase kinase and phosphorylase caused by $\alpha$-methyl-5-HT in hepatocytes.

Since 5-HT has anabolic effects on hepatic glucose metabolism in vivo [12] and on isolated hepatocytes in vitro, the question arises whether antagonists of 5-HT receptors may predispose to impaired glucose tolerance and/or hyperglycaemia. The atypical or second-generation antipsychotic drugs clozapine and olanzapine, which are commonly used for the treatment of various mental disorders, predispose to type 2 diabetes [19] and they also cause acute insulin resistance in animal models after acute exposure [21]. These drugs differ from other atypical antipsychotics in their broad affinity for a wide range of receptors, including 5-HT and muscarinic receptors $[2,35]$. We show in this study that olanzapine and clozapine counteract the inactivation of phosphorylase caused by $\alpha$-methyl-5-HT. Although therapeutic levels of these drugs in serum are in the submicromolar range, olanzapine accumulates in the liver to concentrations of up to $10 \mu \mathrm{mol}$ or higher, which is several-fold higher than plasma concentrations [39]. Various lines of evidence suggest that selective serotonin reuptake inhibitors improve glycaemic control in human type 2 diabetes, independently of their effect on body weight $[9,40]$. The present finding that antipsychotic drugs that predispose to insulin resistance and diabetes counteract the anabolic effects of serotonergic agonists raises the question of the physiological role of serotonin in regulating hepatic glucose metabolism, particularly in conditions of compromised glucose homeostasis.
Acknowledgements This work was supported by project grant and equipment grant support from Diabetes UK.

Duality of interest The authors have declared that there is no conflict of interest with regard to the content of this paper.

\section{References}

1. Veenstra-VanderWeele J, Anderson GM, Cook EH (2000) Pharmacogenetics and the serotonin system: initial studies and future directions. Eur J Pharmacol 410:165-181

2. Pauwels PJ (2000) Diverse signalling by 5-hydroxytryptamine (5HT) receptors. Biochem Pharmacol 60:1743-1750

3. Hoyer D, Hannon JP, Martin GR (2002) Molecular, pharmacological and functional diversity of 5-HT receptors. Pharmacol Biochem Behav 71:533-554

4. Li Y, Wu XY, Zhu JX, Owyang C (2001) Intestinal serotonin acts as paracrine substance to mediate pancreatic secretion stimulated by luminal factors. Am J Physiol 281:G916-G923

5. Lesurtel M, Graf R, Aleil B et al (2006) Platelet-derived serotonin mediates liver regeneration. Science 312:104-107

6. Endo Y (1984) Induction of hypoglycaemia and accumulation of 5-hydroxytryptamine in the liver after the injection of mitogenic substances into mice. Br J Pharmacol 81:645-650

7. Endo Y (1987) Suppression and potentiation of 5-hydroxytryptophaninduced hypoglycaemia by alpha-monofluoromethyldopa: correlation with the accumulation of 5-hydroxytryptamine in the liver. $\mathrm{Br} \mathrm{J}$ Pharmacol 90:161-165

8. Yamada J, Sugimoto Y, Yoshikawa T, Kimura I, Horisaka K (1995) The involvement of the peripheral 5-HT2A receptor in peripherally administered serotonin-induced hyperglycemia in rats. Life Sci 57:819-825

9. Pestell RG, Crock PA, Ward GM, Alford FP, Best JD (1989) Fenfluramine increases insulin action in patients with NIDDM. Diabetes Care 12:252-258

10. Hajduch E, Rencurel F, Balendran A, Batty IH, Downes CP, Hundal HS (1999) Serotonin (5-hydroxytryptamine), a novel regulator of glucose transport in rat skeletal muscle. J Biol Chem 274:13563-13568

11. Rattigan S, Dora KA, Colquhoun EQ, Clark MG (1993) Serotonin-mediated acute insulin resistance in the perfused rat hindlimb but not in incubated muscle: a role for the vascular system. Life Sci 53:1545-1555

12. Moore MC, Geho WB, Lautz M, Farmer B, Neal DW, Cherrington AD (2004) Portal serotonin infusion and glucose disposal in conscious dogs. Diabetes 53:14-20

13. Moore MC, Kimura K, Shibata H et al (2005) Portal 5hydroxytryptophan infusion enhances glucose disposal in conscious dogs. Am J Physiol 289:E225-E231

14. Moore MC, DiCostanzo CA, Dardevet D, Lautz M, Farmer B, Neal DW, Cherrington AD (2004) Portal infusion of a selective serotonin reuptake inhibitor enhances hepatic glucose disposal in conscious dogs. Am J Physiol 287:E1057-E1063

15. Moore MC, DiCostanzo CA, Dardevet D, Lautz M, Farmer B, Cherrington $\mathrm{AD}$ (2005) Interaction of a selective serotonin reuptake inhibitor with insulin in the control of hepatic. Am J Physiol 288: E556-E563

16. Niijima A (1981) Visceral afferents and metabolic function. Diabetologia 20(Suppl):325-330

17. Levine RA, Petsch LA, Klatskin G, Giarman NJ (1964) Effect of serotonin on glycogen metabolism in isolated rat liver. J Clin Invest 43:797-809 
18. Zabala MT, Lorenzo P, Alvarez L, Berlanga JJ, Garcai-Ruiz JP (1992) Serotonin increases the cAMP concentration and the phosphoenolpyruvate carboxykinase mRNA in rat kidney, small intestine, and liver. J Cell Physiol 150:451-455

19. American Diabetes Association (2004) Consensus development conference on antipsychotic drugs and obesity and diabetes (Consensus Statement). Diabetes Care 27:596-601

20. Ader M, Kim SP, Catalano KJ et al (2005) Metabolic dysregulation with atypical antipsychotics occurs in the absence of underlying disease: a placebo-controlled study of olanzapine and risperidone in dogs. Diabetes 54:862-871

21. Houseknecht KL, Robertson AS, Zavadoski W, Gibbs EM, Johnson DE, Rollema H (2007) Acute effects of atypical antipsychotics on whole-body insulin resistance in rats: implications for adverse metabolic effects. Neuropsychopharmacology 32: 289-297

22. Martin WH, Hoover DJ, Armento SJ et al (1998) Indole-2carboxamide inhibitors of human liver glycogen phosphorylase. Proc Natl Acad Sci USA 95:1776-1781

23. Aiston S, Hampson L, Gomez-Foix AM, Guinovart JJ, Agius L (2001) Hepatic glycogen synthesis is highly sensitive to phosphorylase activity: evidence from metabolic control analysis. J Biol Chem 276:23856-23866

24. de la Iglesia N, Mukhtar M, Seoane J, Guinovart JJ, Agius L (2000) The role of the regulatory protein of glucokinase in the glucose sensory mechanism of the hepatocyte. J Biol Chem 275:1059710603

25. Aiston S, Andersen B, Agius L (2003) Glucose 6-phosphate regulates hepatic glycogenolysis through inactivation of phosphorylase. Diabetes 52:1340-1346

26. Aiston S, Hampson LJ, Arden C, Iynedjian PB, Agius L (2006) The role of protein kinase B/Akt in insulin-induced inactivation of phosphorylase in rat hepatocytes. Diabetologia 49:174-182

27. Houghton LA, Atkinson W, Whitaker RP, Whorwell PJ, Rimmer MJ (2003) Increased platelet depleted plasma 5-hydroxytryptamine concentration following meal ingestion in symptomatic female subjects with diarrhoea predominant irritable bowel syndrome. Gut 52:663-670

28. Blum I, Vered Y, Graff E et al (1993) The influence of meal composition on plasma serotonin and norepinephrine concentrations. Metabolism 41:137-140
29. Ismaiel AM, Titeler M, Miller KJ, Smith TS, Glennon RA (1990) 5-HT1 and 5-HT2 binding profiles of the serotonergic agents alpha-methylserotonin and 2-methylserotonin. J Med Chem 33:755-758

30. Oikonomakos NG (2002) Glycogen phosphorylase as a molecular target for type 2 diabetes therapy. Curr Protein Peptide Sci 3:561586

31. Hampson LJ, Agius L (2005) Increased potency and efficacy of combined phosphorylase inactivation and glucokinase activation in control of hepatocyte glycogen metabolism. Diabetes 54:617-623

32. Van Schaftingen E (1995) Involvement of phosphorylase kinase inhibition in the effect of resorcinol and proglycosyn on glycogen metabolism in the liver. Eur J Biochem 234:301-307

33. Balasubramanian S, Paulose CS (1998) Induction of DNA synthesis in primary cultures of rat hepatocytes by serotonin: possible involvement of serotonin S2 receptor. Hepatology 27:62-66

34. Holness MJ, Schofield PS, Sugden MC (1989) Altered interactions between glycogenesis and lipid synthesis after liver resection: specific effects of liver regeneration, coupled with non-specific effects of surgery. Clin Sci (Lond) 76:317-322

35. Ciudad C, Camici M, Ahmad Z, Wang Y, DePaoli-Roach AA, Roach PJ (1984) Control of glycogen synthase phosphorylation in isolated rat hepatocytes by epinephrine, vasopressin and glucagon. Eur J Biochem142:511-520

36. Svenningsson P, Tzavara ET, Liu F, Fienberg AA, Nomikos GG, Greengard P (2002) DARPP-32 mediates serotonergic neurotransmission in the forebrain. Proc Natl Acad Sci USA 99:3188-3193

37. Brady MJ, Nairn AC, Saltiel AR (1997) The regulation of glycogen synthase by protein phosphatase 1 in 3T3-L1 adipocytes. Evidence for a potential role for DARPP-32 in insulin action. J Biol Chem 272:29698-29703

38. Bibb JA, Snyder GL, Nishi A et al (1999) Phosphorylation of DARPP-32 by Cdk5 modulates dopamine signalling in neurons. Nature 402:669-671

39. Aravagiri M, Teper Y, Marder SR (1999) Pharmacokinetics and tissue distribution of olanzapine in rats. Biopharm Drug Dispos 20:369-377

40. Scheen AJ, Paolisso G, Salvatore T, Lefebvre PJ (1991) Improvement of insulin-induced glucose disposal in obese patients with NIDDM after 1-wk treatment with d-fenfluramine. Diabetes Care 14:325-332 